\title{
The organization and evolution of dorsal stream multisensory motor pathways in primates
}

\section{Jon H. Kaas, Omar A. Gharbawie and Iwona Stepniewska*}

Department of Psychology, Vanderbilt University, Nashville, TN, USA

Edited by:

Patrick R. Hof, Mount Sinai School of

Medicine, USA

\section{Reviewed by:}

Todd M. Preuss, Emory University, USA

Marcello Rosa, Monash University, Australia

\section{*Correspondence:}

Iwona Stepniewska, Department of Psychology, Vanderbilt University, 301 Wilson Hall, 11121 st Avenue South, Nashville, TN 37203, USA.

e-mail: iwona.stepniewska

@vanderbilt.edu
In Prosimian primates, NewWorld monkeys, and OldWorld monkeys microstimulation with half second trains of electrical pulses identifies separate zones in posterior parietal cortex (PPC) where reaching, defensive, grasping, and other complex movements can be evoked. Each functional zone receives a different pattern of visual and somatosensory inputs, and projects preferentially to functionally matched parts of motor and premotor cortex. As PPC is a relatively small portion of cortex in most mammals, including the close relatives of primates, we suggest that a larger, more significant PPC emerged with the first primates as a region where several ethologically relevant behaviors could be initiated by sensory and intrinsic signals, and mediated via connections with premotor and motor cortex. While several classes of PPC modules appear to be retained by all primates, elaboration and differentiation of these modules likely occurred in some primates, especially humans.

Keywords: microstimulation, posterior parietal cortex, behavior, motor cortex, visual cortex, sensorimotor processing, anatomical tracers

\section{INTRODUCTION}

The dorsal stream of sensorimotor processing involves several cortical regions that are especially enlarged and differentiated in primates. As originally proposed, the dorsal stream of visuomotor processing included projections of a specific array of extrastriate visual areas into posterior parietal cortex (PPC), which in turn relayed to motor, premotor, and prefrontal areas of frontal cortex (Ungerleider and Mishkin, 1982). Visual cortex in primates is greatly expanded compared to most mammals, and in macaque monkeys, as many as 35 visual areas have been proposed (Felleman and Van Essen, 1991). The contributions to PPC primarily come from a collection of visual areas (Boussaoud et al., 1990; Kaas and Morel, 1993, Born and Bradley, 2005; Kaskan and Kaas, 2007) that are especially involved in processing information about visual motion. The somatosensory areas that contribute to the dorsal stream involve subdivisions of anterior parietal cortex that are uniquely distinct in primates, and newly defined somatosensory areas of the cortex of the lateral sulcus (Qi et al., 2002; Disbrow et al., 2003; Coq et al., 2004). Motor cortex in primates includes primary motor cortex (M1), dorsal (PMD), and ventral (PMV) premotor areas, which have proposed subdivisions, the supplementary motor area, and several motor areas in cingulate cortex (Wu et al., 2000). PPC subregions project to parts of M1, PMD, and PMV (Petrides and Pandya, 1984; TannéGariépy et al., 2002; Fang et al., 2005; see Luppino and Rizolatti, 2001 for review). The dorsal stream pathway was originally called the "where" pathway, as this pathway appeared to be especially involved in determining where objects were located and their spatial relationships, but it has been subsequently called the "how" pathway, as it appeared to be more closely involved in planning and initiating appropriate hand and arm movements in reaching and grasping of objects, and other actions (Goodale and Milner, 1992).
As a key region in the dorsal stream of sensory processing for action, there has been a great deal of interest in the functional organization of PPC, mostly in macaque monkeys (e.g., Andersen and Buneo, 2002; Orban et al., 2006), but also in humans (e.g., Disbrow et al., 2007; Shikata et al., 2008; for review see Grefkes and Fink, 2005). Much of the collected evidence suggests that subdivisions of PPC are specialized for different actions. A caudomedial region of the cortex of the intraparietal sulcus in macaques, the parietal reach region (PRR) appears to be largely involved in reaching (Batista et al., 1999), a lateral intraparietal region (LIP) in directing gaze toward places of interest (Colby et al., 1996), and anterior intraparietal region (AIP) in grasping and manipulating objects (Sakata et al., 1995). Most recently, the ventral intraparietal area (VIP) has been implicated in defensive movements of the head and arm to protect the head (Cooke et al., 2003).

Our own studies have provided new evidence for somewhat different functional subdivisions of PPC, as well as anatomical evidence that functionally compatible zones of PPC and motor and premotor cortex are directly interconnected, and share cortical somatosensory and thalamic connections. In addition, members of three major branches of primate evolution, Prosimian galagos, owl and squirrel monkeys of the New World anthropoids, and macaque monkeys of the Old World anthropoids appear to have similar arrangements of functionally distinct parietal-frontal networks. Thus, these networks were likely present in early primates and retained in all these branches. We were able to distinguish functionally specific zones in both PPC and frontal cortex by using an electrical stimulation procedure that has been used effectively in frontal cortex by Graziano et al. (2002), i.e., $500 \mathrm{~ms}$ trains of electrical pulses delivered via microelectrodes. These "long trains" of electrical pulses produce complex sequences of movements from motor and premotor cortex, whereas the usual $50-60 \mathrm{~ms}$ short trains that have been widely used for mapping the somatotopy 
of motor cortex (e.g., Wu et al., 2000) only produce the initial part of the sequence. In our hands, $60 \mathrm{~ms}$ trains of stimulation usually failed to produce any movements from PPC, but $500 \mathrm{~ms}$ long trains were quite effective in both PPC and in motor and premotor cortex, even in anesthetized primates. Thus, we used long-train stimulation to identify zones in frontal cortex and PPC that were functionally similar, and used injections of anatomical tracers to study the connections of these zones. The results support the concept that PPC of all primates contains nodes in functionally distinct networks that mediate several different types of ethologically relevant behaviors.

\section{THE ORGANIZATION AND CONNECTIONS OF MOVEMENT DOMAINS IN PPC IN PROSIMIAN GALAGOS}

Much of our research on PPC and frontal motor cortex has been on Prosimian galagos. Early primates 60-70 mya diverged into a line that lead to present-day Prosimians, a line to the present-day tarsiers, which are not available for experimental study, and a line to early anthropoids that later diverged into New World monkeys and Old World monkeys together with apes and humans (Martin, 1990). Prosimians include lemurs, lorises, and galagos. Of the Prosimians, galagos have been the most available for research, and thus the most studied. Although Prosimian brains are considered to most closely resemble early primates, they are larger than the brains of early primates. However, Prosimian brains have fewer fissures than most anthropoid species and the ratio of the Prosimian brain to its body size is nearly half of that in anthropoid species (Jerison, 1973). While all brains of modern species have likely been modified and specialized compared to those of early ancestors, galago brains appear to have changed the least, and cortical organization may have changed relatively little from that of early primates. Nevertheless, the array of cortical areas in galagos clearly reflects a primate pattern of organization.
Because there are few cortical fissures, most of the cortical areas in galagos are exposed on the surface and can be illustrated on a dorsolateral view of the brain (Figure 1A). PPC includes cortex between the anterior parietal areas and visual areas of temporal and occipital cortex. Connections with visual areas (DM, V3, MT, MST, MTc, FST) are largely restricted to the caudal half (Krubitzer and Kaas, 1993; Beck and Kaas, 1998; Collins et al., 2001; Fang et al., 2005). In contrast, the rostral half of PPC receives dense inputs from somatosensory cortex (SC), especially from areas S2 and PV, but also from a narrow belt of cortex caudal to $\mathrm{S1}$, termed here, area 1-2 (Stepniewska et al., 2009b). Areas 1 and 2 of anterior parietal cortex have not been defined in Prosimian primates, but the strip of cortex just caudal to S1 (3b) has connections with S1, and is in the position of area 1 or area 1 plus area 2 previously defined in Old World monkeys. Hence, the tentative name, 1-2. As the caudal half of PPC is interconnected with the rostral half, the rostral half receives both somatosensory and visual (less directly) information. Electrical stimulation evoked movements only from the rostral half of PPC (Stepniewska et al., 2005, 2009a). Long 500 ms trains of electrical stimulation evoked complex movements only from the rostral half of PPC (Figure 1;Stepniewska et al., 2005, 2009a).

Shorter trains of 60 or $120 \mathrm{~ms}$ usually failed to evoke a movement, or evoked only a muscle twitch, or a simple one-joint movement. Movements were typically of contralateral body parts, but sometimes, bilateral movements occurred. The complex movements were of several types that often reflected an ethologically relevant action, and they conformed roughly to the somatotopic pattern, so that hindlimb movements were evoked from the most medial sites and eye and face movements from the most lateral sites in rostral PPC. Movements started 33-100 ms after the onset of stimulation and typically continued to the end or slightly past the end of the 500-ms train of pulses. Most medially in rostral PPC, hindlimb (often in conjunction with forelimb) movements,

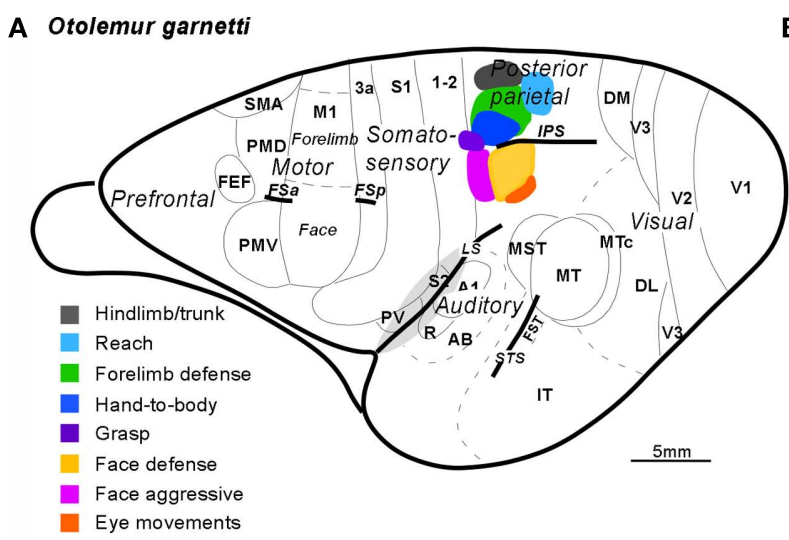

B

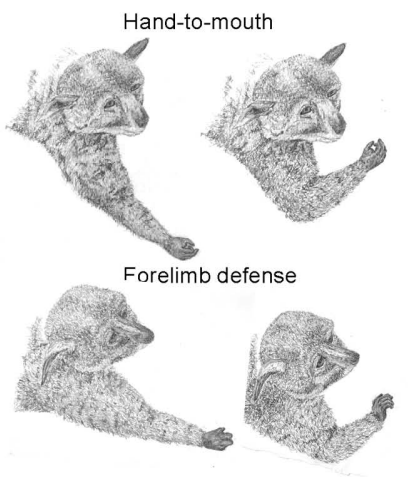

FIGURE 1 | Summary of the posterior parietal cortex (PPC) organization in galagos. (A) Schematic of cortical areas shown on dorsolateral view of the left hemisphere. Functionally distinct movement zones in the rostral half of PPC are marked with colors. Motor regions: primary motor area (M1), dorsal (PMD), and ventral (PMV) premotor areas, supplementary motor area SMA, and frontal eye field FEF. Somatosensory regions: primary somatosensory area $\mathrm{S} 1$ and areas $3 \mathrm{a}, 1-2$, secondary somatosensory area S2, and parietal ventral area PV. Visual region: primary, secondary, and third visual areas V1, $\mathrm{V} 2$, and $\mathrm{V} 3$, dorsomedial (DM), dorsolateral (DL), middle temporal (MT), middle temporal crescent (MTc), middle superior temporal (MST), and inferotemporal (IT) areas. Auditory region: primary A1 and rostral R auditory areas, and auditory belt (AB). Approximate areal borders are marked with thin lines and sulci (intraparietal IPS, frontal anterior FSa, and frontal posterior FSp, cingulate $\mathrm{CgS}$, lateral LS, and superior temporal STS) are marked with thick lines. (B) Two classes of forelimb movements (hand-to-mouth and defensive) evoked by microstimulation of different zones of rostral PPC of galagos. Each segment of drawing depicts first and last phases of a complex forelimb movement (hand-to-mouth and defensive) traced from video recordings. 
as if in climbing, were evoked from a cluster of stimulation sites. This was followed by a more rostral zone for defensive movements of the forelimb (Figure 1B), and a more caudal zone for reaching movements. More laterally, at the rostral tip of the intraparietal sulcus, hand-to-mouth movements (Figure 1B) occurred, followed on the lateral bank of the sulcus and more lateral cortex, by aggressive (rostrally) and defensive (caudally) movements of the face. Eye movements were evoked from a few most lateral sites. Finally, a small zone for grasping movements located rostral to the hand-to-mouth zone was in area $1-2$, as well as in rostral PPC. We almost missed this zone because we typically failed to fully explore area 1-2, as it was considered part of anterior parietal cortex. Movements were not evoked from other parts of area 1-2. Consistent with this result in galagos, a grasping zone was found in area 2 of monkeys (see below).

When tracers were injected into specific function zones in rostral PPC, a different pattern of connections was revealed for each zone (Figure 2; see also Stepniewska et al., 2009b). The face aggressive region had strong connections with PMV, while the face defensive region had strong connections with PMD, as well as some direct visual inputs. The hand-to-mouth region had strong connections with cingulate cortex, as well as M1 and PMD, while the defensive zone had some direct visual inputs. The reaching zone had even more direct visual inputs. All zones had connections with somatosensory areas in the S2-PV region, and widespread connections within PPC. The connections of movement-specific PPC zones activate matching zones in M1 and premotor cortex, as revealed by optically imaging patterns of hemodynamic activity in frontal cortex during electrical stimulation of PPC zones (Stepniewska et al., accepted). Moreover, the functioning of the M1 zones is critical to the functioning of the PPC zones, as stimulation of PPC no longer produced movements after the

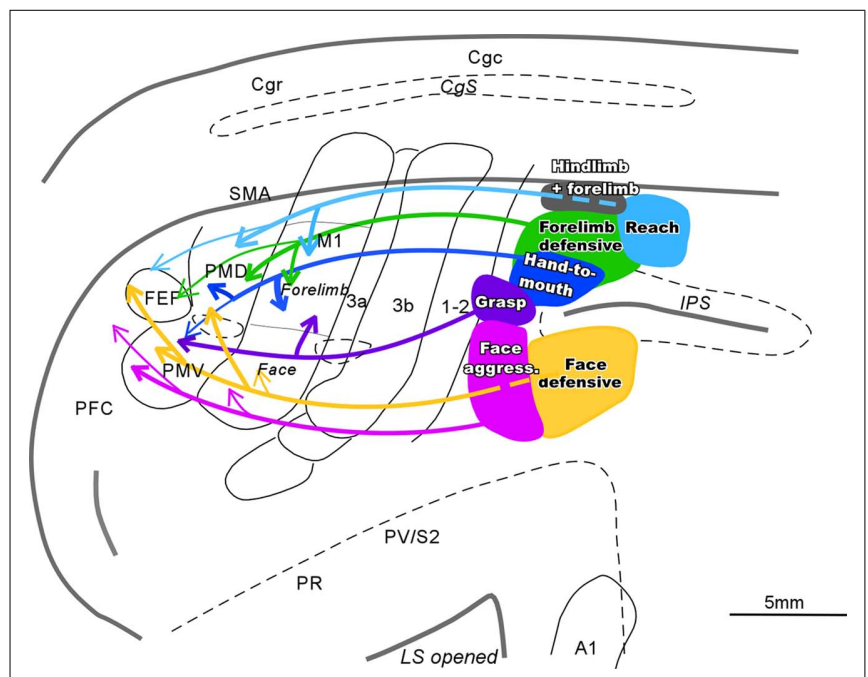

FIGURE 2 | Schematic of parietal-frontal connections of the specific movement zones in PPC of galagos. Functionally distinct movement zones (filled with colors) and their connections (indicated by color coordinated lines) are marked on the flattened view of left cerebral hemisphere. Thick lines represent strong connections, and thin lines represent weak connections. Opened sulci are marked with dashed lines. activity of functionally matched parts of M1 was blocked with muscimol (Stepniewska et al., 2008).

\section{THE ORGANIZATION AND CONNECTIONS OF MOVEMENT DOMAINS IN PPC OF NEW WORLD MONKEYS}

Using the same stimulation and anatomical procedures, functional zones in PPC, and in motor, and premotor cortex, were revealed in New World owl and squirrel monkeys (Gharbawie et al., 2010, 2011). These studies focused on defining reach, defense, and grasp zones, which were found in both PPC and frontal cortex. As in galagos, these three PPC zones were arranged in a mediolateral sequence with a rostrolateral slant in owl and squirrel monkeys (Figure 3). Area 1 has been well defined in owl and squirrel monkeys on the basis of a characteristic representation of the cutaneous receptors of the contralateral body (Merzenich et al., 1978; Sur et al., 1982). We consider a narrow strip of cortex along the caudal border of area 1 to be area 2 , as in macaque monkeys, although the evidence for this cortex being area 2 is limited. This cortex has also been considered to be part of PPC (Padberg et al., 2005). In either case, the grasp zone in owl and squirrel monkeys was centered in cortex identified here as area 2. In addition, the PPC defense region extends into area 2 and even somewhat into area 1. Some of this spread may be due to local spread across areal boundaries of electrical stimulation, but the evidence suggests that parts of area 2 are within the PPC motor movement system. A reach zone was consistently caudal to area 2 and was likely in area 5. In frontal cortex reaching movements were evoked from part of PMD and an adjoining part of M1, defense movements from lateral M1 and part of PMV, and grasping movements from part of the forelimb representation in M1 and PMV. Thus, corresponding movement zones can be identified in PPC, M1, and premotor cortex.

Injections of tracers into more than one functionally defined zone in these New World monkeys (Figure 4) allowed us to make several important observations. First, the connections between frontal and PPC regions were consistently most dense between

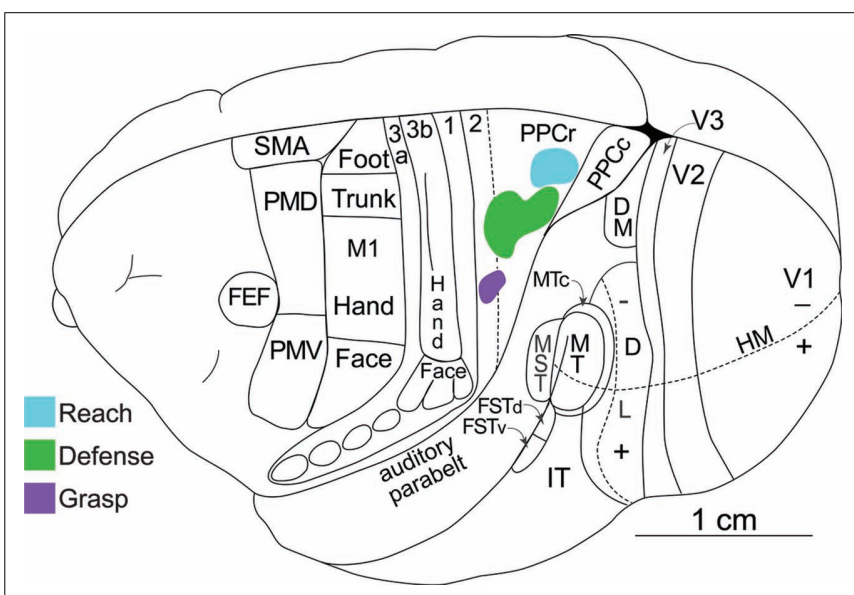

FIGURE 3 | Dorsolateral view of a squirrel monkey brain. The reach, defense, and grasp zones identified with long-train electrical stimulation are arranged in PPC in a caudomedial to rostrolateral pattern. PPCr, rostral PPC and PPCC, caudal PPC. All other conventions are the same as in Figure 1 

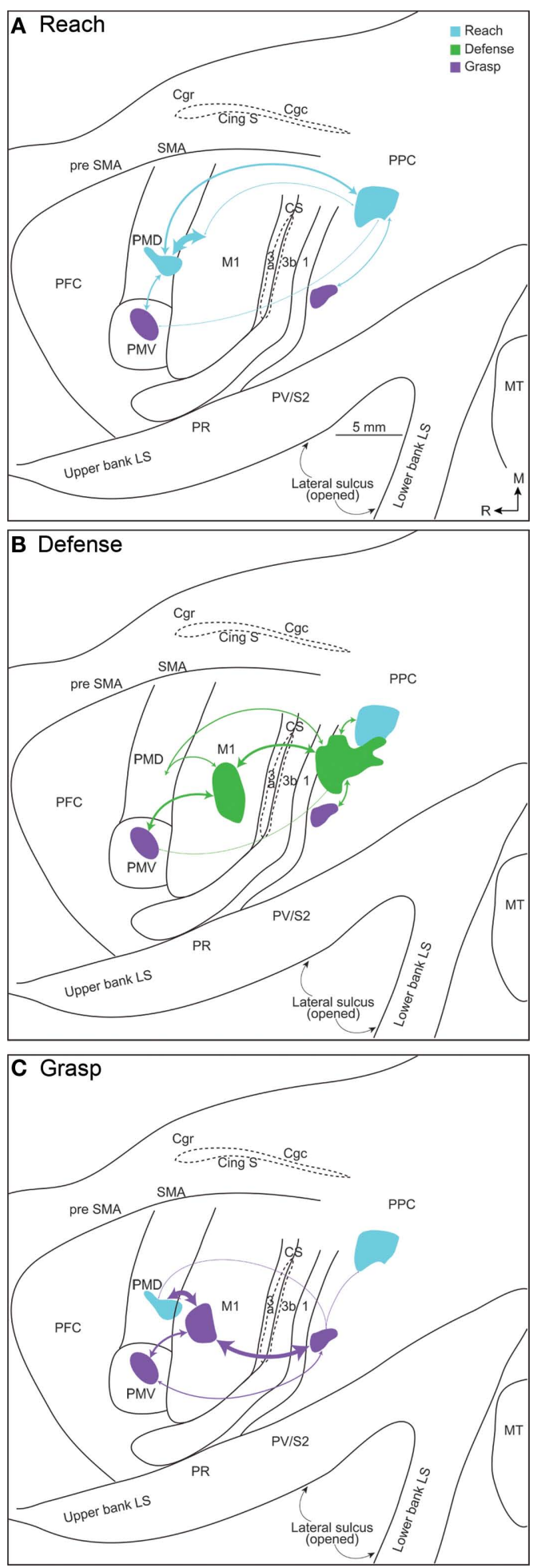

FIGURE 4 | Connections patterns for (A) reach, (B) defense, and (C) grasp zones in frontal cortex and PPC, illustrated on a flattened squirrel monkey cortex. The thickness of each line is proportional to the density of the connection. A characteristic network of parietal-frontal connections supports each constellation of movements. The densest parietal-frontal connections are between zones of similar movements, but weak connections also link dissimilar zones. functionally matched zones. Second, overlapping populations of neurons in especially somatosensory areas in the lateral sulcus (S2, PV, and others) projected to functionally matched zones in frontal cortex and PPC. Thus, reach zones, defense zones, or grasp zones in PPC and frontal cortex share some inputs from other cortical areas and even thalamic nuclei. Third, different functional zones in PPC depend on inputs from somewhat different populations of somatosensory neurons in lateral parietal cortex, and different patterns of visual inputs. Fourth, PPC zones are interconnected. Finally, although all PPC zones receive major inputs from the lateral posterior nucleus, the PPC zones also receive weaker projections from the ventral lateral nucleus of the motor thalamus and to a lesser extent the ventroposterior nucleus of somatosensory thalamus. These results support the conclusion that functionally distinct but interrelated parietal-frontal streams exist in owl and squirrel monkeys.

\section{PPC IN OLD WORLD MACAQUE MONKEYS}

While the connections and neurophysiology of PPC in macaques have been intensively studied, there is only limited information based on long-train electrical stimulation. Cooke et al. (2003) located a defensive movement zone in the intraparietal sulcus in cortex attributed to the VIP. A matching defensive zone was located in M1 (Graziano et al., 2002). In our preliminary, ongoing studies of PPC in macaques, we identified a grasp zone in the cortex just medial and rostral to the tip of the intraparietal sulcus (Figure 5). This grasp zone, however, is not located in cortex commonly identified as PPC, but rather it is in a middle part of area 2. A matching grasp zone has been located in parts of PMV and M1 in macaques (Graziano et al., 2002). The hand portion of area 2 has connections with M1, but these connections were described as sparse (Pons and Kaas, 1986). More recently we have determined that the grasp zone of area 2 in macaques is preferentially connected with the M1 grasp zone and adjacent cortex in the rostral bank of the central sulcus. The connections of VIP are somewhat uncertain, but large injections in the VIP region labeled neurons in both M1 and premotor

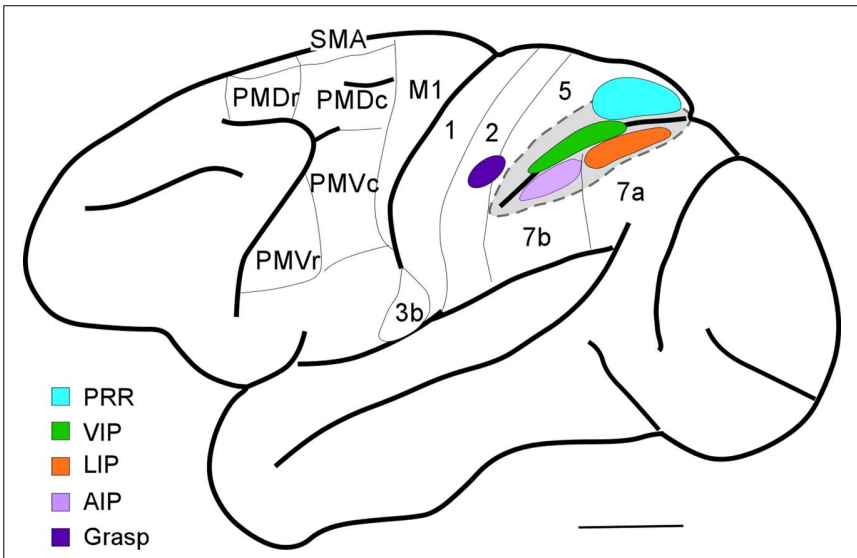

FIGURE 5 | Dorsolateral view of a macaque brain. Note open intraparietal sulcus to show buried areas: PRR, parietal reach region; VIP, ventral intraparietal area; LIP, lateral intraparietal area; and AIP, anterior intraparietal area. The grasp region identified by our long-train microstimulation study in area 2 is also shown. 
cortex (Lewis and Van Essen, 2000) and injections in caudal PMV (F4) labeled neurons in the VIP region (Luppino et al., 1999). The grasp zone in area 2 identified by microstimulation in macaques is close to, but not overlapping the anterior intraparietal area, AIP, which is on the lateral bank of the rostral end of the intraparietal sulcus. Microelectrode recordings indicate that AIP is involved in grasping and manipulating objects in macaque monkeys (Sakata et al., 1995), and AIP projects to a rostral division (F5) of PMV (Luppino et al., 1999). Thus, there is evidence for more than one parietal-frontal pathway for grasping in macaques.

Our results in macaques, owl and squirrel monkeys, and galagos, suggest that the parietal cortex zone where grasping movements are evoked is in area 2, just rostral to parts of PPC that are involved in grasping and manipulation behaviors (area AIP). The portion of area 2 that represents the hand in macaques has connections with motor cortex, as well as with the AIP region (Pons and Kaas, 1986). However, the cortex of area 5 immediately adjoining our proposed area 2 grasp zone is also clearly involved in grasping behaviors, as lesions of this cortex produce a short-term deficit in grasping behavior (Padberg et al., 2010). Overall, the hand representation in area 2, the adjoining part of area 5 on the medial bank of the intraparietal sulcus, and AIP on the lateral bank of the sulcus all appear to be involved in grasping behavior.

Finally, a more caudal region on the medial bank of intraparietal sulcus, the posterior PRR (Andersen and Buneo, 2002) seems a likely locus for a motor reach domain (Galletti et al., 1997), as found in galagos and New World monkeys. If so, the arrangement of reach, defensive, and grasp domains in a caudomedial to rostrolateral sequence in PPC plus area 2 is a feature of members of three major branches of primate evolution, Prosimians, New World monkeys, and Old World monkeys. In addition, there is a wealth of data from functional imaging and other studies supporting the conclusion that PPC in humans also may have dedicated regions for reaching and grasping (e.g., Grol et al., 2007). As the PPC in humans is greatly expanded (Van Essen, 2004; Hill et al., 2010), there is interest in both identifying areas and regions that may be homologous with those in other primates (Grefkes and Fink, 2005; Sereno and Tootell, 2005; Husain and Nachev, 2007; Durand et al., 2009), and in characterizing the elaborations and modifications of these areas and regions in ways that enhance and extend abilities that became important as modern humans evolved, such as the extensive use of tools (Orban et al., 2006; Frey, 2007; Durand et al., 2009; Peeters et al., 2009).

\section{THE EVOLUTION OF PPC}

Posterior parietal cortex is an expanded portion of the cortex in primates, that is the least expanded in Prosimian primates, and the most expanded in humans. The results reviewed here are consistent with the results of many studies of PPC in macaques that provide evidence that $\mathrm{PPC}$ is divided into a number of functionally distinct regions devoted to the initiation and guidance of different types of actions. We have provided evidence for specific parietalfrontal circuits that are involved in reaching, defensive movements, and grasping. Other parietal-frontal circuits involved in behaviors such as directing gaze and bringing food to the mouth, appear to exist as well. Thus, a number of specific circuits appear to be shared by most, or all extant primates, and thus they were likely retained from a common ancestor. These circuits also were elaborated and subdivided in at least some lines of primate evolution to subserve new and different needs, especially in humans to perhaps provide greater flexibility, promote tool use, and the acquisition of other motor skills.

If we take a broader comparative approach, the evidence suggests that the "primate type" of PPC is unique to primates. Primates belong to a branch of mammalian evolution called Euarchontoglires. This line of evolution diverged from other placental mammals some $80-90$ mya to produce the radiation of present-day primates, as well as the closer relatives of primates, tree shrews, and flying lemurs. More distant relatives of primates include rodents and lagomorphs (rabbits; Murphy et al., 2001). While little is known about the brains of flying lemurs, studies on rodents, lagomorphs, and tree shrews all suggest that primates emerged from ancestors that had little PPC (Disbrow et al., 2007; Remple et al., 2007). Thus, PPC was not the important part of the cortex that it is in primates.

Cortical organization in tree shrews has been extensively studied in an effort to infer the organization of cortex in the immediate ancestors of primates. Both tree shrews and early primates adapted to a greater reliance on vision by expanding visual cortex so that temporal and occipital regions of cortex were enlarged. Presentday tree shrews have a number of visual areas (Lyon et al., 1998), and other regions of visual cortex that have not yet been characterized (Figure 6). An auditory region may contain several areas. SC includes a primary area $\mathrm{S} 1$ or area $3 \mathrm{~b}$, a narrow area $3 \mathrm{a}$ just rostral to $\mathrm{S} 1$, and a narrow band of SC just caudal to $\mathrm{S} 1$ in the position of area 1 or area $1-2$ of primates (Remple et al., 2006, 2007). Only a narrow band of cortex posterior to caudal SC can be reasonably defined as PPC, as it has a mixture of somatosensory and visual inputs, and projects to frontal motor cortex. However, some of the higher-order visual areas project directly to motor and frontal cortex, as do somatosensory areas. Thus, motor cortex functions

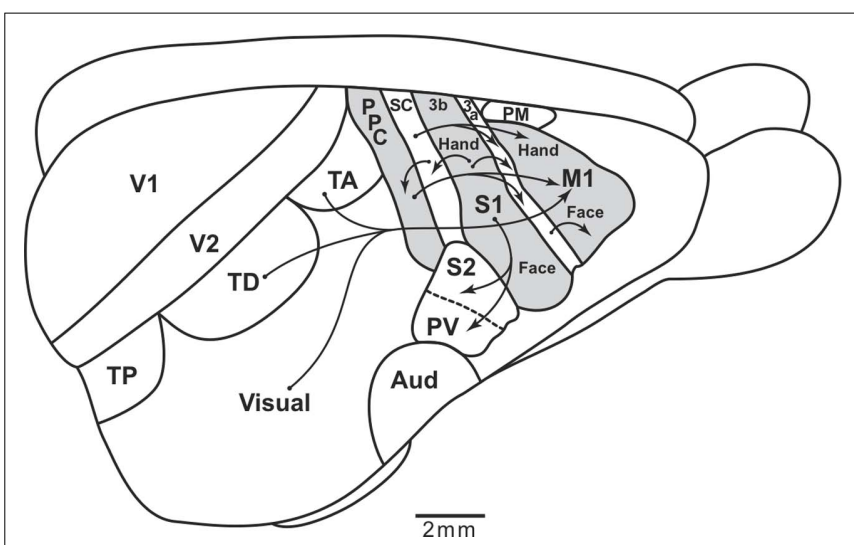

FIGURE 6 | Sensorimotor cortical pathways of tree shrews. The extent of posterior parietal cortex is very limited, and most visual and somatosensory information reaches motor cortex (M1) directly from somatosensory and visual areas. The caudal somatosensory area, SC, is a likely homolog of area 1-2 of galagos. TP, TD, and TA are proposed posterior, dorsal, and anterior temporal visual areas. S1 and S2, primary and secondary somatosensory areas. PV, the parietal ventral somatosensory area. Aud, auditory cortex. PM, premotor cortex. Arrows depict some of the relevant cortical connections. Based on Remple et al. (2006). 
are more directly guided by visual and somatosensory information in tree shrews than in primates. Since PPC is only a small part of cortex, it likely has a much more limited role. Rodents such as rats and squirrels also have proportionately little PPC and have direct visual and somatosensory inputs into motor and premotor cortex. Thus, an expanded PPC, with separate modules and connections with motor and premotor cortex form parallel networks that support different actions. Those networks evolved as early primates emerged, and their basic components have been retained in most or all extant primates. This is not to say that an expanded and functionally important PPC did not evolve independently in other branches of mammalian evolution, in carnivores for example, but this did not happen in other Euarchontoglires.

\section{WHAT IS PRIMATE PPC FOR?}

The functional streams for different ethologically relevant behaviors start in PPC. They depend on different mixtures of somatosensory and visual inputs, with some auditory (Cohen et al., 2004) and vestibular inputs (Snyder et al., 1998). There are also thalamic inputs, some of which are from the motor thalamus. Feedback from prefrontal cortex may be very important, as motor behavior can be internally driven as well as sensory driven (Munoz and Everling, 2004). Outputs to premotor and primary motor cortex are critical, as these areas are responsible for subcortical projections that mediate the behaviors via terminations in premotor and motor neuronal pools of the brainstem and spinal cord. While motor functions are distributed across parietal and frontal regions, it seems likely that sensory inputs consistently activate a number of network nodes in PPC, and that they are often in competition with

\section{REFERENCES}

Andersen, R. A., and Buneo, C. A. (2002). Intentional maps in posterior parietal cortex. Annu. Rev. Neurosci. 25, 189-220.

Andersen, R. A., and Cui, H. (2009). Intention, action planning, and decision making in parietal-frontal circuits. Neuron 63, 568-583.

Batista, A. P., Buneo, C. A., Snyder, L. H., and Andersen, R. A. (1999). Reach plans in eye-centered coordinates. Science 285, 257-260.

Beck, P. D., and Kaas, J. H. (1998). Cortical connections of the dorsomedial visual area in prosimian primates. $J$. Comp. Neurol. 398, 162-178.

Born, R. T., and Bradley, D. C. (2005). Structure and function of area MT. Annu. Rev. Neurosci. 28, 157-189.

Boussaoud, D., Ungerleider, L. G., and Desimone, R. (1990). Pathways for motion analysis: cortical connections of the medial superior temporal and fundus of the superior temporal visual areas in the macaque. J. Comp. Neurol. 29, 462-495.

Cohen, Y. E., Cohen, I. S., and Gifford, G. W. (2004). Modification of LIP activity by predictive auditory and visual cues. Cereb. Cortex 14, 1287-1301.
Colby, C. L., Duhamel, J. R., and Goldberg, M. E. (1996). Visual, presaccadic, and cognitive activation of single neurons in monkey lateral intraparietal area. J. Neurophysiol. 76, 2841-2852.

Collins, C. E., Stepniewska, I., and Kaas, J. H. (2001). Topographic patterns of v2 cortical connections in a prosimian primate (Galago garnetti). J. Comp. Neurol. 431, 155-167.

Cooke, D. F., Taylor, C. R., Moore, T., and Graziano, M. S. A. (2003). Complex movements evoked by microstimulation of the ventral intraparietal area. Proc. Natl. Acad. Sci. U.S.A. 100, 6163-6168.

Coq, J. O., Qi, H., Collins, C. E., and Kaas, J. H. (2004). Anatomi$\mathrm{cal}$ and functional organization of somatosensory areas of the lateral fissure of the New World titi monkey (Callicebus moloch). J. Comp. Neurol. 476, 363-387.

Disbrow, E., Hinkley, L., Padberg, J., and Krubitzer, L. (2007). "Hand use and evolution of posterior parietal cortex in primates," in Evolution of Nervous Systems, Vol. 4, Primate, eds J. H. Kaas and T. M. Preuss (London: Elsevier), 407-415.

each other for initiating different, often mutually incompatible behaviors. The outcome of this competition is possibly mediated by inhibitory connections between the PPC nodes, perhaps when one of the nodes is favored by a pattern of inputs that produced a stronger, earlier activation (see Snyder et al., 2010). Thus, PPC is positioned to have the major role in determining the winner of a range of competing circuits for modes of action. Subsequent activations could tip the balance so that new actions replace or supplement ongoing actions, and thus a reach can be followed by a grasp, and a grasp by retrieval to the mouth. The specifics of these actions would seem to depend on the activation via PPC of specialized circuits in premotor and motor cortex, and their subcortical outputs. We suggest that this activating role for PPC has become progressively more important, varied and complex in some lines of primate evolution, but a major role for PPC in grasping, defensive, and reaching behaviors was already in place with the emergence of the first primates. In earlier ancestors, such behaviors were likely mediated more directly by sensory and other inputs to motor frontal areas, but in early primates PPC provided an overlay of the decision making process, which became more diversified and dominant in anthropoid primates, especially humans. Nevertheless, frontal motor areas, in conjunction with prefrontal cortex, contribute to the decision process (Romo et al., 2004; Schall et al., 2004; Schall, 2005; Wunderlich et al., 2009), and prefrontal cortex may be especially important when stored information rather than incoming sensory information determines the outcome. Decision making has been considered, along with sensorimotor transformations and movement planning, as one of the functions of PPC (Andersen and Cui, 2009).

Disbrow, E., Litinas, E., Recanzone, G. H., Padberg, J., and Krubitzer, L. (2003). Cortical connections of the secondary somatosensory area and the parietal ventral area in macaque monkeys. J. Comp. Neurol. 462, 382-399.

Durand, J.-B., Peeters, R., Norman, J. F., Todd, J. T., and Orban, G. A. (2009). Parietal regions processing visual 3D shape extracted from disparity. $\mathrm{Neu}$ roimage 46, 1114-1126.

Fang, P. C., Stepniewska, I., and Kaas, J. H. (2005). Ipsilateral cortical connections of motor, premotor, frontal eye, and posterior parietal fields in a prosimian primate, Otolemur garnettii. J. Comp. Neurol. 490, 305-333.

Felleman, D. J., and Van Essen, D. C. (1991). Distributed hierarchical processing in the primate cerebral cortex. Cereb. Cortex 1, 1-47.

Frey, S. H. (2007). "Neurological specialization for manual gesture and tool use in humans," in Evolution of Nervous Systems, Vol. 5, Primates, eds J. H. Kaas and T. M. Preuss (London: Elsevier), 395-405.

Galletti, C., Fattori, P., Kutz, D. F., and Battaglini, P. P. (1997). Arm movement-related neurons in the visual area $\mathrm{V} 6 \mathrm{~A}$ of the macaque superior parietal lobule. Eur. J. Neurosci. 9, 410-413.

Gharbawie, O. A., Stepniewska, I., Burish, M. J., and Kaas, J. H. (2010). Thalamocortical connections of functional zones in posterior parietal cortex and frontal cortex motor regions in New World monkeys. Cereb. Cortex 20, 2391-2410.

Gharbawie, O. A., Stepniewska, I., and Kaas, J. H. (2011). Cortical connections of functional zones in posterior parietal cortex and frontal cortex motor regions in New World monkeys. Cereb. Cortex. PMID 21263034. [Epub ahead of print].

Goodale, M. A., and Milner, A. D. (1992). Separate visual pathways for perception and action. Trends $\mathrm{Neu}$ rosci. 15, 20-25.

Graziano, M. S. A., Taylor, C. S. R., and Moore, T. (2002). Complex movements evoked by microstimulation of precentral cortex. Neuron 34, 841-851.

Grefkes, C., and Fink, G. R. (2005). The functional organization of the intraparietal sulcus in humans and monkeys. J. Anat. 207, 3-17. 
Grol, M. J., Majdandzic, J., Stephan, K. E., Verhagen, L., Dijkerman, H. C., Bekkering, H., Verstraten, F. A., and Toni, I. (2007). Parietofrontal connectivity during visually guided grasping. J. Neurosci. 27, 11877-11887.

Hill, J., Inder, T., Neil, J., Dierker, D., Harwell, J., and Van Essen, D. (2010). Similar pattern of cortical expansion during human development evolution. Proc. Natl. Acad. Sci. U.S.A. 107, 13135-13140.

Husain, M., and Nachev, P. (2007). Space and the parietal cortex. Trends Cogn. Sci. (Regul. Ed.) 11, 30-36.

Jerison, H. J. (1973). Evolution of the Brain and Intelligence. New York: Academic Press.

Kaas, J. H., and Morel, A. (1993). Connections of visual areas of the upper temporal lobe of owl monkeys: the MT crescent and dorsal and ventral subdivisions of FST. J. Neurosci. 13, 534-546.

Kaskan, P. M., and Kaas, J. H. (2007). Cortical connections of the middle temporal and the middle temporal crescent visual areas in prosimian galagos (Otolemur garnettii). Anat. Rec. (Hoboken) 290, 349-366.

Krubitzer, L., and Kaas, J. H. (1993). The dorsomedial visual area of owl monkeys: connections, myeloarchitecture, and homologies in other primates. J. Comp. Neurol. 334, 497-528.

Lewis, J. W., and Van Essen, D. C. (2000). Mapping of architectonic subdivisions in the macaque monkey, with emphasis on parieto-occipital cortex. J. Comp. Neurol. 428, 79-111.

Luppino, G., Muvata, A., Govoni, P., and Matelli, M. (1999). Largely segregated parietofrontal connections linking rostral intraparietal cortex (areas AIP and VIP) and the ventral premotor cortex (areas F5 and F4). Exp. Brain Res. 128, 181-187.

Luppino, G., and Rizolatti, G. (2001). The cortical motor system. Neuron 31, 889-901.

Lyon, D. C., Jain, N., and Kaas, J. H. (1998). Cortical connections of striate and extrastriate visual areas in tree shrews. J. Comp. Neurol. 401, 109-128.

Martin, R. D. (1990). Primate Origins and Evolution. A Phylogenetic Reconstruction. Princeton: University Press.

Merzenich, M. M., Kaas, J. H., Sur, M., and Lin, C. S. (1978). Double representation of the body surface within cytoarchitectonic areas $3 \mathrm{~b}$ and 1 in "SI" in the owl monkey (Aotus trivirgatus). J. Comp. Neurol. 181, 41-73.

Munoz, D. P., and Everling, S. (2004). Look away: the anti-saccade task and voluntary control of eye movement. Nat. Rev. Neurosci. 5, 218-228.

Murphy, W. J., Eizirik, E., O'Brien, S., Madsen, O., Scally, M., Douady, C. J., Teeling, E., Ryder, O. A., Stanhope, M. J., de Jong, W. W., and Springer, M. S. (2001). Resolution of the early placental mammal radiation using Bayesian phylogenetics. Science 294, 2348-2351.

Orban, G. A., Claeys, K., Nelissen, K., Smans, R., Sunaert, S., Todd, J. T., Wardak, C., Durand, J.-B., and Vanduffel, W. (2006). Mapping the parietal cortex of human and nonhuman primates. Neuropsychologia 44, 2647-2667.

Padberg, J., Disbrow, E., and Krubitzer, L. (2005). The organization and connections of anterior and posterior parietal cortex in titi monkeys: do New World monkeys have an area 2? Cereb. Cortex 12,1938-1963.

Padberg, J., Recanzone, G., Engle, J., Cooke, D., Goldring, A., and Krubitzer, L. (2010). Lesions in posterior parietal area 5 in monkeys result in rapid behavioral and cortical plasticity. J. Neurosci. 30, 12918-12935.

Peeters, R., Simon, L., Nelissen, K., Fabbri-Destro, M., Vanduffel, W., Rizzolatti, G., and Orban, G. A. (2009). The representation of tool use in humans and monkeys: common and uniquely human features. J. Neurosci. 29, 11523-11539.

Petrides, M., and Pandya, D. N. (1984). Projections to the frontal cortex from the posterior parietal region in the rhesus monkey. J. Comp. Neurol. 228, 105-116.

Pons, T. P., and Kaas, J. H. (1986). Corticocortical connections of area 2 of somatosensory cortex in macaque monkeys: a correlative anatomical and electrophysiological study. $J$. Comp. Neurol. 248, 313-335.

Qi, H. X., Lyon, D. C., and Kaas, J. H. (2002). Cortical and thalamic connections of the parietal ventral somatosensory area in marmoset monkey (Callithrix jacchus). J. Comp. Neurol. 443, 168-182.

Remple, M. S., Reed, J. L., Stepniewska, I., and Kaas, J. H. (2006). Organization of frontoparietal cortex in the tree shrew (Tupaia belangeri). I. Architecture, microelectrode maps, and corticospinal connections. $J$. Comp. Neurol. 497, 133-154.

Remple, M. S., Reed, J. L., Stepniewska, I., Lyon, D. C., and Kaas, J. H. (2007). The organization of frontoparietal cortex in the tree shrew (Tupaia belangeri): II. Connectional evidence for a frontal-posterior parietal network. J Comp. Neurol. 501, 121-149.
Romo, R., Hernandez, A., and Zaino, A. (2004). Neuronal correlates of a perceptual decision in ventral premotor cortex. Neuron 41, 165-173.

Sakata, H., Taira, M., Murata, A., and Mine, S. (1995). Neural mechanisms of visual guidance of hand action in the parietal cortex of the monkey. Cereb. Cortex 5, 429-438.

Schall, J. D. (2005). Decision making. Curr. Biol. 15, R9-R11.

Schall, J. D., Thompson, K. G., Bichot, N. P., Murthy, A., and Sato, T. R. (2004). "Visual processing in the macaque frontal eye field," in The Primate Visual System, eds J. H. Kaas and C. E. Collins (Boca Raton, FL: CRC Press), 205-259.

Sereno, M. I., and Tootell, R. B. (2005). From monkeys to humans: what do we now know about brain homologies? Curr. Opin. Neurobiol. 15, 135-144.

Shikata, E., Mc Namara, A., Sprenger, A., Hamzei, F., Glauche, V., Buchel, C., and Binkofski, F. (2008). Localization of human intraparietal areas AIP, CIP, and LIP using surface orientation and saccadic eye movement tasks. Hum. Brain Mapp. 29, 411-421.

Snyder, H. R., Hutchison, N., Nyhus, E., Curran, T., Banich, M. T., and O'Reilley, R. C. (2010). Neural inhibition enables selection during language processing. Proc. Natl. Acad. Sci. U.S.A. 107, 16483-16488.

Snyder, L. H., Grieve, K. L., Brotchie, P., and Andersen, R. A. (1998). Separate body-and world-referenced representations of visual space in parietal cortex. Nature 394, 887-891.

Stepniewska, I., Fang, P. C., and Kaas, J. H. (2005). Microstimulation reveals specialized subregions for different complex movements in posterior parietal cortex of prosimian galagos. Proc. Natl. Acad. Sci. U.S.A. 102, 4878-4883.

Stepniewska, I., Fang, P. C., and Kaas, J. H. (2009a). Organization of posterior parietal cortex in galagos: I. Functional zones identified by microstimulation. J. Comp. Neurol. 517, 765-782.

Stepniewska, I., Cerkevich, C. M., Fang, P. C., and Kaas, J. H. (2009b). Organization of posterior parietal cortex in galagos: II. Ipsilateral cortical connections of physiologically identified zones within anterior sensorimotor region. J. Comp. Neurol. 517, 783-807.

Stepniewska, I., Gharbawie, O. A., Burish, M. J., and Kaas, J. H. (2008). "Deactivation of primary motor cortex abolishes movements evoked from premotor and posterior parietal areas in primates," in FENS, Geneva.

Sur, M., Nelson, R. J., and Kaas, J. H. (1982). Representations of the body surface in cortical areas $3 \mathrm{~b}$ and 1 of squirrel monkeys: comparisons with other primates. J. Comp. Neurol. 211, 177-192.

Tanné-Gariépy, J., Rouiller, E. M., and Boussaoud, D. (2002). Parietal inputs to dorsal versus ventral premotor areas in the macaque monkey: evidence for largely segregated visuomotor pathways. Exp. Brain Res. 145, 91-103.

Ungerleider, L. G., and Mishkin, M. (1982). "Two cortical visual systems," in Analysis of Visual Behavior, eds D. G Ingle, M. A. Goodale, and R. J. Q. Mansfield (Cambridge, MA: MIT Press), 549-586.

Van Essen, D. (2004). "Organization of visual areas in macaque and human cerebral cortex," in The Visual Neurosciences, eds L. M. Chalupa and J. S. Werner (Cambridge, MA: MIT Press), 507-521.

Wu, C. W.-H., Bichot, N. P., and Kaas, J. H. (2000). Converging evidence from microstimulation, architecture, and connections for multiple motor areas in the frontal and cingulate cortex of prosimian primates. J. Comp. Neurol. 423, 140-177.

Wunderlich, K., Rangel, A., and O'Doherty, J. P. (2009). Neural computations underlying action-based decision making in the human brain. Proc. Natl. Acad. Sci. U.S.A. 106, 17199-17204.

Conflict of Interest Statement: The authors declare that the research was conducted in the absence of any commercial or financial relationships that could be construed as a potential conflict of interest.

Received: 16 February 2011; paper pending published: 10 March 2011; accepted: 01 June 2011; published online: 13 June 2011.

Citation: Kaas JH, Gharbawie $O A$ and Stepniewska I (2011) The organization and evolution of dorsal stream multisensory motor pathways in primates. Front. Neuroanat. 5:34. doi: 10.3389/fnana.2011.00034

Copyright @ 2011 Kaas, Gharbawie and Stepniewska. This is an open-access article subject to a non-exclusive license between the authors and Frontiers Media $S A$, which permits use, distribution and reproduction in other forums, provided the original authors and source are credited and other Frontiers conditions are complied with. 